\title{
La comunicación de los alimentos genéticamente modificados: estado, regulación y lecciones
}

\section{The communication of genetically modified food: status, regulation and lessons}

\author{
Gerardo Carrera-Castañoa \\ a Centro de Biotecnología y Genómica de Plantas, Universidad Politécnica de Madrid-Instituto Nacional de Investigación y Tecnología \\ Agraria y Alimentaria, Madrid, España
}

\section{Resumen}

Los organismos genéticamente modificados (OGM) constituyen un concepto equívoco y diferencialmente definido por las distintas legislaciones y sensibilidades que está presente en nuestro léxico desde hace más de 30 años. Con un campo semántico tecnológico y amenazador, la modificación genética y los alimentos GM han sido adoptados en diferentes regiones del mundo, aunque la aceptación por parte de los consumidores y la opinión pública ha sido, por lo general, baja. El debate por la seguridad de este tipo de alimentos está todavía abierto y regido por dos posturas predominantes: el principio de equivalencia por un lado, en el que se da un mayor peso al producto y que ha sido adoptado por Estados Unidos y la Administración de Alimentos y Medicamentos (FDA), y el principio de cautela, en el que se da un mayor peso a la tecnología y que ha sido adoptado por la Unión Europea y la Autoridad Europea de Seguridad Alimentaria (EFSA). La comunidad científica hoy día se decanta por el principio de equivalencia, pero al constituir este un debate complejo y multidisciplinar se requiere un método comunicacional que se sitúe más allá del Modelo de Déficit y un debate abierto y racional.

Palabras clave: Alimentos genéticamente modificados; OGM; comunicación; transgénesis; legislación.

\begin{abstract}
Genetically modified organisms (GMOs) constitute an equivocal concept and differentially defined by legislations and sensitivities that has been present in our lexicon for more than 30 years. With a technological and threatening semantic field, genetic modification and GM food have been adopted in different regions of the world, although the acceptance by consumers and public opinion has been, in general, low. The debate over the safety of this type of food is still open and governed by two predominant positions: the principle of equivalence on the one hand, which gives a greater weight to the product and has been adopted by the United States and the Food and Drugs Administration (FDA), and the precautionary principle on the other hand, which gives more weight to the technology and has been adopted by the European Union and the European Food Safety Authority (EFSA). Today, the scientific community opts for the principle of equivalence but, since this is a complex and multidisciplinary debate, a communication method beyond the Deficit Model and an open and rational debate are required.
\end{abstract}

Key Words: Genetically modified food; GMOs; communication; transgenesis; legislation. 


\section{Pasado y presente de la modificación genética}

Los organismos genéticamente modificados (OGM) constituyen un concepto extraño, novedoso, que sin embargo lleva ya más de 30 años en boca de la comunidad científica: por ejemplo, hace 36 años se produjo la primera introducción de un gen exógeno en una planta (HerreraEstrella, Depicker, Van Montagu y Schell, 1983). Quizá la propia terminología utilizada al referirnos a este hito, "introducción" y "exógeno", tenga parte de la culpa de las reticencias que causan los alimentos transgénicos en la población en general. Son palabras que hacen referencia a lo foráneo, a lo, de nuevo, extraño. Se introducen cosas en la comida: conservantes, hormonas, -la mal utilizada traducción- pesticidas, y con los OGM se introducen genes. $Y$ además se introducen genes exógenos, que no son inherentes al organismo. Lo foráneo, lo de fuera, causa desconfianza desde el origen de la civilización, y si a lo foráneo le unimos un problema comunicacional, una no coincidencia de lenguas, de usos o costumbres -los bárbaros y el Imperio romano- lo que encontramos es entonces un enquistamiento de la relación dentro-fuera difícil de solucionar una vez el primer encuentro sucedió hace tiempo. $Y$ como se indicaba al comienzo, el primer encuentro sucedió hace más de 30 años.

La modificación genética es en sí misma un concepto escurridizo. Se ha modificado genéticamente desde que el hombre pasó de cazador-recolector a agricultor. La domesticación de animales y plantas llevó, por un proceso de selección y cruzamientos intra- e interespecíficos, a la modificación genética de diferentes especies (Doebly, Gaut y Smith, 2006). Más tarde se generaron nuevas variedades con características de interés mediante la exposición de plantas a agentes mutagénicos, como rayos gamma y agentes químicos. Pero aunque los individuos resultantes de la domesticación o de los tratamientos mutagénicos son organismos modificados genéticamente no son Organismos Genéticamente Modificados.

Según la Directiva 2001/18/CE del Parlamento Europeo y del Consejo, de 12 de marzo de 2001, sobre la liberación intencional en el medio ambiente de organismos modificados genéticamente y por la que se deroga la Directiva 90/220/CEE del Consejo, un OGM es "el organismo, con excepción de los seres humanos, cuyo material genético haya sido modificado de una manera que no se produce naturalmente en el apareamiento ni en la recombinación natural". Así, referido por ejemplo a un cultivo, una planta modificada genéticamente será aquella manipulada según las técnicas consideradas de manipulación genética, o sea, que no se producen en la naturaleza -el bombardeo de rayos $X$ no se da en la naturaleza, pero en ella los rayos $X$ sí pueden producir mutaciones espontáneas-, como son: las técnicas de recombinación del ácido nucleico, consistentes en la inserción de moléculas de ácido nucleico en vectores (virus, plásmido bacteriano) y su incorporación en un organismo hospedador; la incorporación directa de material heridatario en un organismo (microinyección, macroinyección y microencapsulación); y las técnicas de fusión de células, incluida la fusión de protoplastos, o de hibridación mediante métodos que no se producen naturalmente. $Y$ quedarían excluidos de esta definición los organismos obtenidos por técnicas no causantes de modificación genética (fertilización in vitro; conjugación, transformación y transducción, e inducción poliploide) y los obtenidos por ciertas técnicas de modificación genética natural como son la mutagénesis y la fusión de células vegetales de individuos que puedan hibridarse mediante métodos tradicionales. Según esta definición, por tanto, la primera planta considerada un OGM se obtendría en 1909, con la primera realización de una fusión de protoplastos (Küster, 1909).

Si en 1983 se consigue la primera planta transgénica, pronto la transgénesis se entendió como un modelo de negocio. El 1994 se comercializó el primer alimento transgénico, el tomate de maduración lenta Flavour Saver. La transgénesis de cultivos alimentarios comenzó a constituirse como una posibilidad real de introducir caracteres de interés de manera dirigida, a la par que abrió un nuevo abanico de aplicaciones al poder traspasar funciones de especies vegetales lejanas u organismos de otros reinos a las plantas. Hoy día, las aplicaciones de los cultivos GM, que en el 2017 alcanzaron las 189,8 millones de hectáreas (ISAAA, 2017), pasan por la resistencia a insectos (plantas BT, plantas que expresan lectinas), tolerancia a herbicidas (glifosato, glufosinato, y otros herbicidas no selectivos que permiten desplazar a los herbicidas selectivos, de perfil desfavorable ambientalmente), mejora de la productividad y rendimiento, mejora de la calidad nutritiva (arroz dorado con precursores de la vitamina A, libre de patentes; tomate enriquecido en antioxidantes), control de enfermedades virales (resistencia derivada del patógeno), tolerancia al estrés ambiental (sequía, altas y bajas temperaturas, alta o baja radiación), producción de frutos más resistentes (tomates y plátanos de larga vida con silenciamiento del contenido endógeno de etileno), plantas biorreactoras (producción de moléculas de interés industrial y sanitario como insulina, hormona de crecimiento, anticuerpos) y mejoras con fines ornamentales (rosas y claveles azules), entre otras. 


\section{Percepción pública de los alimentos GM}

El debate sobre la seguridad en la salud de los alimentos GM sigue hoy día abierto, y la percepción pública varía enormemente según la región del mundo. Europa, por ejemplo, es uno de los estandartes a nivel global contra los transgénicos, teniendo uno de los datos regionales de adopción más bajos: 131.535 hectáreas de un solo evento transgénico, MON810, un maíz resistente al taladro, en el año 2017 (ISAAA, 2017). Según los datos del Eurobarómetro del año 2010 sobre biotecnología, un $61 \%$ de la población de la Unión Europea se muestra intranquilo con respecto a los alimentos GM y contrario a su fomento, y un $59 \%$ piensa que no son seguros para la salud humana. En España, país a la cabeza del cultivo transgénico con una adopción de maíz transgénico de más del $30 \%$ de su maíz cultivado (Lucht, 2015) y con el $91 \%$ del maíz transgénico de toda la Unión Europea (ISAAA, 2017), un $51 \%$ de la población se encuentra intranquilo con respecto a estos alimentos, un $49 \%$ opina que no deberían fomentarse, y un $44 \%$ que no son seguros para la salud. Van Eenennaam y Young (2018) explican que se produjo un acentuamiento del rechazo de los alimentos GM por parte de la opinión pública a raíz de la crisis de la encefalopatía espongiforme bovina a finales de los 80 y de nuevo en los 90 .

A diferencia de Europa, en América los Estados Unidos, Canadá y algunos países latinoamericanos (Brasil y Argentina a la cabeza) han adoptado los cultivos GM. A nivel global, Estados Unidos está a la cabeza del cultivo con un $94 \%$ de su soja transgénica, un $91 \%$ de algodón y un 89\% de maíz en el año 2018 (United States Department of Agriculture, 2018), siguiéndole Brasil. Sin embargo, a pesar de la gran adopción y su presencia en los supermercados, la aceptación por parte de los consumidores como alimento seguro según una encuesta del Pew Research Center (2015) está en un 37\%. Este valor contrasta con que un $88 \%$ de cientíicos de la American Association for the Advancement of Science (AAAS) crean que los alimentos GM son seguros, lo que explica la gran adopción de estos cultivos ya que el modelo de legislación está basado en la opinión científica y en el principio de "equivalencia" y no en el principio de "cautela", como se explicará en el apartado siguiente.

En China, país que concentra el $20 \%$ de la población mundial, solo un $11,9 \%$ de los consumidores tienen una visión positiva hacia los alimentos GM frente a un 46,7\% que se posiciona en contra (Cui y Shoemaker, 2018). Sin embargo, el esfuerzo del gobierno, cuyo apoyo a la biotecnología ha sido muy fuerte en los últimos años, está haciendo que junto a Bangladés sea uno de los países donde la aceptación esté creciendo más. Todo lo contrario que en Filipinas o la India, siendo este último el cuarto país con mayor superficie de cultivos transgénicos. En estos dos países la oposición pública hacia los alimentos GM está creciendo e incluso se suceden los actos vandálicos (Cui y Shoemaker, 2018; Jayaranman y Jia, 2012).

En África el progreso es lento y el problema es que apenas existe una opinión pública: en 2005 un estudio mostró que de 7000 personas encuestadas el $80 \%$ no conocía el significado de la palabra "biotecnología" (Van Eenennaam y Young, 2018), pero parece haber una nueva receptividad a los alimentos GM en algunos países africanos como Benín, Níger y Nigeria, que parecen seguir la senda iniciada por Sudáfrica y continuada por Kenia y Uganda (Wesseler, Smart, Thomson y Ziberman, 2017).

\section{Debate sobre la seguridad}

La percepción predominantemente negativa sobre los alimentos GM existe a pesar de que varios paneles científicos han concluido muchas veces que estos son seguros, 0 al menos tan seguros como los alimentos producidos de otras formas, y a que llevan introducidos 25 años en la cadena alimentaria humana. Hasta ahora, no se ha encontrado ninguna evidencia científica de efectos nocivos de ningún cultivo GM aprobado, y es así como, por ejemplo, en un análisis de la composición de 129 eventos transgénicos autorizados en Estados Unidos no se pudo detectar ninguna diferencia significativa entre la planta modificada y su contraparte no modificada (Herman y Price, 2013).

La transgénesis en sí misma no produce ningún peligro a la salud del consumidor; donde podrían existir riesgos asociados es en la proteína específica codificada por el gen introducido como recoge la Royal Society (2016) sobre este tema. Es así como una variedad "natural" de patata, obtenida por mutagénesis o por cruzamiento y selección, con altos índices de solanina en el tubérculo podría provocar daños en la salud, al igual que una patata transgénica que exprese un gen que codifica para un alérgeno que procede de un insecto. En ambos casos, el efecto nocivo deriva del producto, y no del método de obtención. Sin embargo, en este punto radican las diferentes legislaciones sobre alimentos GM. En Estados Unidos, la Administración de Alimentos y Medicamentos (FDA) se rige por la noción de "sustancia equivalente" para garantizar la seguridad de los alimentos nuevos, sin importar el método de obtención ("natural" o GM): "si se encuentra que un alimento nuevo es sustancialmente 
equivalente a un alimento existente, se puede concluir que el alimento es tan seguro como el alimento convencional" (FAO, 1996).

Los fabricantes y distribuidores del nuevo alimento serán los encargados de garantizar los niveles de seguridad de este enfrentándose a graves sanciones en su incumplimiento. En la Unión Europea, según la Directiva 2001/18/CE del Parlamento Europeo y del Consejo, de 12 de marzo de 2001, sobre la liberación intencional en el medio ambiente de organismos modificados genéticamente y por la que se deroga la Directiva 90/220/CEE del Consejo, se erige un principio de precaución, o de cautela -"Se ha tenido en cuenta el principio de cautela a la hora de redactar la presente Directiva y debe tenerse en cuenta cuando ésta se aplique", Preámbulos- focalizado únicamente en los alimentos GM, por el cual los desarrolladores del alimento han de demostrar ante la Autoridad Europea de Seguridad Alimentaria (EFSA) su inocuidad antes de su introducción en el mercado. $Y$ más aún, ya no solo rige el principio de cautela por causas científicas, con la Directiva (UE) 2015/412 del Parlamento Europeo y del Consejo de 11 de marzo de 2015 por la que se modifica la Directiva 2001/18/CE en lo que respecta a la posibilidad de que los Estados miembros restrinjan o prohíban el cultivo de organismos modificados genéticamente (OMG) en su territorio, cualquier Estado miembro puede restringir por cualquier razón (incluso ideológica) la entrada de los OGM en su territorio.

Ambas agencias, la FDA y la EFSA, reclaman al obtentor de la nueva variedad GM información sobre el evento (variedades utilizadas, insertos, métodos de transformación). Tras esto se realiza (FDA) o se reclama (EFSA) un análisis de la composición nutricional del alimento que incluye contenido en aminoácidos, ácidos grasos, fibra, y contenido de minerales y agua. Además se lleva a cabo un estudio de toxicidad y alergenicidad mediante un análisis previo de homología con proteínas que producen alergia y el aislamiento y ensayos in vitro -como ensayos de liberación de basófilos- del nuevo producto introducido, y estudios de alimentación durante 90 días en roedores -no necesarios en la Unión Europea en alimentos no GM-, tiempo consensuado como suficiente para detectar problemas crónicos a largo plazo (DeFrancesco, 2013).

La realidad es que hay dos formas de enfrentarse a los alimentos GM que han sido adoptadas por Estados Unidos y la Unión Europea, y es el enfrentarse al riesgo real 0 al riesgo percibido. $Y$ este enfrentarse no es una decisión científica, sino social: si miramos el riesgo real de los alimentos GM, entendido como enfermedad, hospitalización y muerte, este es muy bajo, y es que hoy los problemas en alimentación están más relacionados con contaminaciones alimentarias de patógenos humanos. El riesgo percibido es el que procede de la tecnología, de lo foráneo como se comentaba en la introducción. Y la modificación genética hoy día es un concepto extraño, que se expande por la opinión pública como un peligroso temor tecnológico.

\section{Lecciones de comunicación de los alimentos GM y la salud}

El problema de la comunicación de la salud y los alimentos GM es que la partícula GM connota una gran cantidad de temas adyacentes y de ámbito ambiental que se han de tratar junto a los efectos en la salud humana, como son el uso de plaguicidas, las políticas agrícolas, los pequeños agricultores contra las multinacionales, las patentes 0 la producción de comida. Es decir, como el debate es multidisciplinario requiere de una comunicación compleja, lo que significa que no funciona únicamente con dar información al público como indican varios estudios (Cuite, Aquino y Hallman, 2005). Esto no significa que el papel de los medios de comunicación no sea importante, pues una prensa en contra de los alimentos GM tendría una profunda repercusión en la opinión pública, pero sí indica el requerimiento de otro tipo de comunicación más directa y responsable, mediada por la propia comunidad científica.

Blancke, Grunewald y De Jaeger (2017) aconsejan que el mensaje principal en una comunicación sobre alimentos GM sea el de que la manipulación genética solo es un conjunto de métodos de mejora genética, como la mejora clásica (cruces y selección) o la mutagénesis. Los autores indican que de ahí se desprenden tres implicaciones: la primera es que no tiene sentido oponerse a la manipulación genética -una tecnología no es lo mismo que sus aplicaciones-; la segunda es que solo es posible analizar los efectos en la salud para cada aplicación en particular, caso por caso; la tercera es que el producto final necesita ser evaluado asimismo caso por caso según sus propios riesgos y méritos -y es que si un tomate con alto contenido en antioxidantes, con efectos positivos contra la aparición de tumores, es seguro en los distintos ámbitos de salud y ambientales, es irrelevante que se haya obtenido por mejora clásica, mutagénesis o transgénesis-. Explican que con estas tres implicaciones aceptadas, creada una base común comunicador-audiencia, se consigue fácilmente desacoplar tecnología con otras implicaciones, importantes, pero que no tienen una relación directa con la tecnología y sí con algunos usos: ahora sí, uso de plaguicidas, patentes, pequeños agricultores, modelos agrícolas. 
Landrum y Hallman (2017) también acentúan el papel comunicacional de la comunidad científica y la formación de comunicadores y proponen un conjunto de puntos a tener en cuenta para una comunicación eficaz para aliviar la discusión sobre los alimentos GM. Así, destacan que la comunicación científica está para informar y no para persuadir, lo cual puede provocar respuestas negativas; hace falta moverse más allá del Modelo de Déficit de la comunicación científica, y es que en este caso parece que no es suficiente intensificar la información dada sobre modificación genética; es necesario conocer el punto de inicio de la audiencia, y es que aunque no hay que sobreestimar los conocimientos de la gente común sobre ciencia, tampoco hay que sobresimplificar conceptos; reconocer puntos de vista subjetivos en cuestiones que no entren en el conocimiento científico (como aspectos éticos); y elegir la audiencia sabiamente, no aceptando cualquier evento para enfrentarse al debate.

Estudiando las respuestas de los consumidores chinos, Cui y Shoemaker (2018) hacen una interesante apreciación. Existe una brecha entre el conocimiento científico en ciertas cuestiones y la opinión pública, y "la conclusión de las ciencias naturales generalmente es solo verdad, mientras que la cultura y las actitudes pueden ser diversas, pudiendo ser influidas por creencias religiosas y/o partidos políticos". Las diferencias en la opinión pública sobre temas sensibles, en este caso sobre alimentos GM, deberían ser respetadas; pero a la vez es necesario una dirección de ese respeto por parte del gobierno, entidades públicas, comunidad científica y medios para incluir a la población, a la opinión pública, en el diálogo social sobre esta tecnología. Es necesario este diálogo para, con un ejercicio de comunicación cercano al Modelo de Déficit, pero de manera laxa, como recuerdan Landrum y Hallman (2017), trasformar el primer debate caótico y desconfiante en uno racional.

Y es quizá este diálogo primero que discuten los autores para la situación china el que falta en Europa, como se desprende del estudio que elabora Garcés (2016), quien observa analizando medios de comunicación europeos que, habiendo sido los OGM un tema de intensa discusión en los últimos años del siglo XX, hoy día, a pesar de la existencia de la Web 2.0, el debate está desapareciendo de los medios digitales, y con ello, posiblemente, de la opinión pública.

\section{Referencias Bibliográficas}

Blancke, S., Grunewald, W., \& De Jaeger, G. (2017). Deproblematizing 'GMOs': suggestions for communicating about genetic engineering. Trends in Biotechnology, 35(3), 185-186. doi: 10.1016/j.tibtech.2016.12.004
Comisión Europea. (2010). Eurobarometer 73.1. Biotechnology. Recuperado de http://ec.europa. eu/commfrontoffice/publicopinion/archives/ebs/ ebs_341_en.pdf

Cui, K., \& Shoemaker, S. P. (2018). Public perception of genetically-modified (GM) food: A Nationwide Chinese Consumer Study. Science of Food, 2(10), 1-8. doi:10.1038/s41538-018-0018-4

Cuite, C. L., Aquino, H. L., \& Hallman, W. K. (2005). An empirical investigation of the role of knowledge in public opinion about GM food. International Journal of Biotechnology, 7, 178-194. doi:10.1504/ IJBT.2005.006453

DeFrancesco, L. (2013). How safe does transgenic food need to be? Nature Biotechnology, 31(9), 794802. doi:10.1038/nbt.2686

Doebley, J. F., Gaut, B. S., \& Smith, B. D. (2006). The molecular genetics of crop domestication. Cell, 127(7), 1309-1321. doi:10.1016/j.cell.2006.12.006

Garcés, M. J. P. (2016). Genetically modified crops 2.0: the decline of media controversy in digital journalism. Mètode, 6, 28-34. doi:10.7203/metode.6.3899

Herman, R.A., \& Price, W.D. (2013). Unintended compositional changes in genetically modified crops: 20 years of research. Journal of Agricultural and Food Chemistry, 61(48), 11695-11701. doi:10.1021/jf400135r

Herrera-Estrella, L., Depicker, A., Van Montagu, M., \& Schell, J. (1983). Expression of chimaeric genes transferred into plant cells using a Ti-plasmid-derived vector. Nature, 303, 209-213.

Jayaranman, K., \& Jia, H. (2012). GM phobia spreads in South Asia. Nature Biotechnology, 30(11), 10171019. doi:10.1038/nbt1112-1017a

Küster, E. (1909). Über die Verschmelzung nackter Protoplasten. Berichte der Deutschen Botanischen Gesellschaft, 27(10), 589-598. doi:10.1111/j.1438-8677.1909.tb06760.x

Landrum, A. R., \& Hallman, W. K. (2017). Engaging in effective science communication: A response to Blancke et al. on deproblematizing GMOs. Trends in Biotechnology, 35(5), 378-379. doi:10.1016/j. tibtech.2017.01.006

Lucht, J. M. (2015). Public acceptance of plant biotechnology and GM crops. Viruses, 7(8), 42544281. doi:10.3390/v7082819 
Organización de las Naciones Unidas para la Alimentación y la Agricultura (FAO). (1996). Joint FAO/WHO Expert Consultation on Biotechnology and Food Safety. Recuperado de http://www.fao.org/ag/agn/ food/pdf/biotechnology.pdf

Parlamento Europeo. (2001). Directiva 2001/18/ CE del Parlamento Europeo y del Consejo, de 12 de marzo de 2001. Recuperado de https://eur-lex.europa.eu/legal-content/es/ ALL/?uri=CELEX\%3A32001L0018

Parlamento Europeo. (2015). Directiva (UE) 2015/412 del Parlamento Europeo y del Consejo de 11 de marzo de 2015. Recuperado de https://eur-lex.europa. eu/legal-content/ES/TXT/?uri=CELEX\%3A32015L0412

Pew Research Center. (2015). Public and scientists' views on science and society. Recuperado de https://www.pewresearch.org/science/2015/01/29/ public-and-scientists-views-on-science-and-society/

Royal Society. (2016). Is it safe to eat GM crops? Recuperado de https://royalsociety.org/topics-policy/ projects/gm-plants/is-it-safe-to-eat-gm-crops/

Servicio Internacional para la Adquisición de Aplicaciones Agrobiotecnológicas. (2017). Global status of commercialized biotech/GM crops in 2017: biotech crop adoptionsurges as economic benefits accumulate in 22 years. ISAAA Brief, 53. Recuperado de http:// www.isaaa.org/resources/publications/briefs/53/ download/isaaa-brief-53-2017.pdf

United States Department of Agriculture. (2018). Recent trends in GE adoption. Recuperado de http://www. ers.usda.gov/data-products/adoption-of-geneticallyengineered-crops-in-the-us/recent-trends-in-geadoption.aspx

Van Eenennaam, A., \& Young, A. E. (2018). Public perception of animal biotechnology. En H. Niemann, \& C. Wrenzycki (Eds.), Animal Biotechnology 2: Emerging breeding technologies (1era. Ed., pp. 275-303). Berlín, Alemania: Springer.

Wesseler, J., Smart, R. D., Thomson, J., \& Ziberman, D. (2017). Foregone benefits of important food crop improvements in Sub-Saharan Africa. PLoS One, 12(7), e0181353. doi:10.1371/journal.pone.0181353 